\title{
ENTREPRENEURIAL ENERGY AND OPPORTUNITIES EXISTING IN SPACE
}

\author{
David Leong \\ University of Canberra, Bruce ACT 2617, Australia \\ E-mail: u3221961@uni.canberra.edu.au \\ Received October 2020; accepted December 2020
}

\begin{abstract}
The space within which the entrepreneurs exist is filled with risks, opportunities and other environmental resources. Scholars have argued that entrepreneurs are constantly discovering and identifying value potentials because significant values arise from the existence of positive externalities which can be captured and exploited. Positive externalities or opportunities can create substantial and desirable gains if they can be monetized, leveraged and exploited. These externalities refer to the natural environmental resources within the space where the entrepreneurs operate. From the perspective of space, this paper will explore the emergence of opportunities or risks within the space through the theoretical lens of structuration and complex science and will, specifically, discuss the collision and the meeting of opportunities with the entrepreneurs at the nexus from the perspective of entrepreneurial energy excitation. Entrepreneurship originates from a nexus of individuals and opportunities. The unique juncture in space or nexus in which the entrepreneurs and opportunities exist is central to the study of entrepreneurship because it is in this juncture or nexus that identification and evaluation of risks and opportunities take place. It is the subsequent human actions, driven by the level of entrepreneurial energy that will lead to the myriad of possible venture pathways. For risks, entrepreneurs perceive them and will subsequently work towards mitigation or avoidance through various measures. The exploitation of opportunities is concerned with acquiring and employing resources in the space to gain certain advantages. Likewise, with risks, entrepreneurs perceive the risks and work towards the mitigation or avoidance of the perceived risk in the venture pathways. In this paper, entrepreneurship is viewed through the structuration and complexity science lens to present the entrepreneurial venture as the instantiated outcome of the entrepreneur-opportunity interaction through time and space. Complexity science offers a theoretical lens for exploring the complex interdependencies of a complex, and adaptive pluralistic world with irreversibility and randomness being the rules- dynamical systems in the natural and physical worlds. The key central concept of complexity is that interactivities between parts of open systems that creates unpredictable and seemingly random patterns. While the history of the open system is relevant in understanding its dynamics, the specific isolation of individual parts of the system does not reveal the system's casual mechanisms. The paper explores whether how entrepreneurial energy arises from the convergence/ collision of entrepreneurs with opportunities in a dynamical, unpredictable and random way in a nexus in space.
\end{abstract}

\section{Research paper}

Keywords: Entrepreneurship; Risks; Opportunities; Complex science

Reference to this paper should be made as follows: Leong, D. (2020). Entrepreneurial Energy and Opportunities Existing in Space, Journal of Entrepreneurship, Business and Economics, 8(2), 196218. 


\section{Entrepreneurial Energy Perspective}

Modelling the dynamics of how entrepreneurial pathways emerge and how the convergence of opportunities and risks direct human actions - vision, strategic organizing and tactical organizing (Lichtenstein et al., 2006) provides insights into the understanding of entrepreneurship in a dynamically complex system. The intermediating part in this move to action when there is a convergence in the nexus between the entrepreneur and the opportunity is entrepreneurial energy. Such convergence will cause agitation and excitement to shift the entrepreneur to action, or the lack of agitation will lead the entrepreneur to forgo the opportunity. The simultaneous shift in all three modes indicates a punctuation event in the operative space. See Diagram 1 defining the operative space where the entrepreneur function, with the constant bombardment of opportunities, risks and resources.

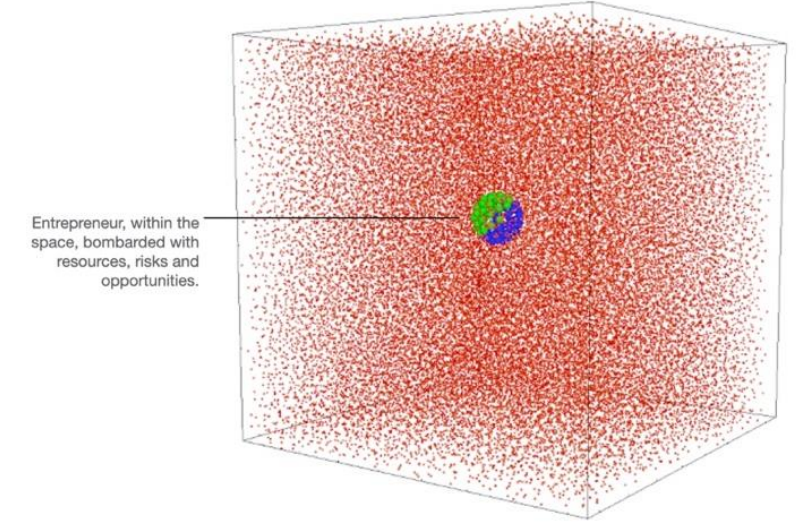

Diagram 1. operative space in which entrepreneur functions (source: author's elaboration) 
This punctuation is defined as an emergence event. Therefore, entrepreneurial energy is a pervasive positive force and plays a critical role in the entrepreneurs' cognitive and motivational process to sustain a momentum in action. In short, its energy in motion for the entrepreneurs.

Entrepreneurial energy is the driving force for entrepreneurial venturing. Most theoretical frameworks in entrepreneurship emphasize that entrepreneurial passion drives entrepreneurial actions and efforts. Passion is an important psychological construct because it is often characterized as a deep, positive and intense feeling (Collewaert et al., 2016) or driving force or, metaphorically, "the fire of desire" (Gielnik et al., 2015). Entrepreneurial passion reflects the positive and intense feelings for activities associated with roles that are meaningful to the entrepreneur's self-identity (Cardon \& Stevens, 2009) and the affective feelings that are intertwined with the entrepreneur's definition and identity of themselves.

Theoretically, it is not adequate to account that passion indeed helps explain the gap in understanding entrepreneurs' motivation and the sustained interest along the entrepreneurial pathway. Scholarly investigations of passion in entrepreneurship assume various outcomes of passion, without explaining clearly the pathways through which passion leads to these outcomes (Stroe, 2017). In this paper, the aim is to demonstrate that it is not just passion but entrepreneurial energy that is at work. It is the energy in motion that is at work. Entrepreneurial energy excitation, happens in the nexus of the entrepreneur and the opportunity, hold the passion, sustenance and dedication to the ventures. With the entrepreneurial energy comes the 
energy to explore and exploit against the environmental context of risk and uncertainties. The process of exploration and exploitation involves strategies. The entrepreneurial energy is the energy of motion- kinetic energy.

In this paper, the concept of entrepreneurial energy as "energy in motion and movement, generating consciously accessible intense positive feelings experienced by engagement in entrepreneurial activities and capacity for doing and in the process generate heat, work and passion. Passion includes feelings that are consciously experienced, positive, and intense, such as excitement, elation, or joy. In order for such feelings to be qualified as passion, they must be experienced for something that is meaningful to the self-identity of the entrepreneur."

In summary, the entrepreneurial energy is the force that spurs and drives the entrepreneurs to action.

\section{From the Perspective of Structuration Theory}

Structuration theory and the domain of entrepreneurship focus on the nexus of individuals and social systems (Sarason et al., 2006) within the space, the insights of structuration theory are particularly applicable to the nature of the entrepreneurial venturing. Applying structuration theory to entrepreneurship, entrepreneurs both create and are created by the process of entrepreneurial venturing and therefore, can be constructively viewed as a duality (Sarason et al., 2006). The mechanism of this co-creation involves the recursive and iterative interactions of entrepreneur and opportunity over in space over time. This can be characterized as a continuously evolving 199 
cycle of entrepreneur/space inter-dependence or a duality alternating to evolve and shape the social construct. This is also at the same nexus where the convergence of the entrepreneurial energy arises as a result of the meeting of the entrepreneur and the opportunity. The entrepreneur, opportunity and space do not exist separate from each other and cannot be understood independently (Sarason et al., 2006). See Diagram 2.

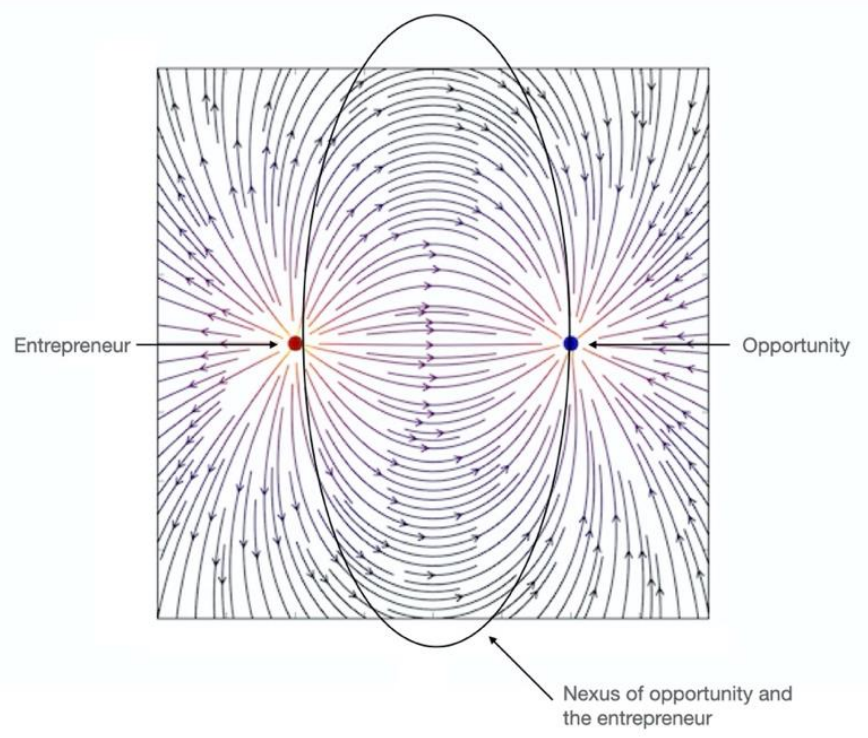

Diagram 2. nexus of Opportunity and entrepreneur (source: author's elaboration)

The iterative cycle of the entrepreneurial process operates through the existing domain of knowledge and experience, on one part and reflexive actions, spurred by the entrepreneur's level of entrepreneurial energy (Sarason et al., 2006). Therefore, entrepreneurial behaviour is not defined by inherent traits or habits alone -with an innate habit of alertness to opportuni- 
ties but through interactions with the opportunities. When the opportunities are perceived, some may lead to action, others may not. The dynamical interplay of creating opportunities and new ventures through actions based on subjective interpretations of risks and opportunities in the space cause excitement with the incipient of entrepreneurial energy. The focus is on this iterative and reflexive transformation of resources, not only on the entrepreneur or only on the nature of the risks and opportunity presented in space but by their dynamically interlinking, interactivity and interlacing to form new opportunities and pathways.

The nexus in which entrepreneurs and the risks and opportunities coexist and then converge is subject to discovery, evaluation, and exploitation and these actions of exploitation that follow will be initiated only when there is adequate entrepreneurial energy generated to trigger actions.

Ventures pathways are shaped within the nexus of interaction between the entrepreneur and the entrepreneurial ecosystem/ space over time. This dynamism of interactions may be characterized by the recursive and iterative cycles of interpretation, action, consequence, and reflection. An entrepreneur's initial conception of an entrepreneurial venture is likely to change over time and is not deterministically fixed as the venture progresses. The instantiated venture will be unique at any point in time as both the venture itself and the entrepreneur's conception thereof, changes. (Sarason et al., 2006). Entrepreneurs' intentionality and beliefs drive their action. So, intention and actions are key to the start of any venture. The critical differences between entrepreneurship and entrepreneurial thinking lie in the fact 
that entrepreneurship is about actions and intentions, and entrepreneurial thinking is about attitude and beliefs. Behind entrepreneurial actions are entrepreneurial intentions. Behind entrepreneurial intentions are known as entrepreneurial attitudes. Behind entrepreneurial attitudes are deep cognitive structures. Behind deep cognitive structures are deep beliefs. (Krueger, 2007). Behind entrepreneurial actions are entrepreneurial energy powering the action and sustaining the momentum to entrepreneurial venturing. Entrepreneurial energy rises and ebbs according to the level of excitement from the intentions and beliefs at the point in space-time, where the initial idea of venture creation emerges. Where the entrepreneurial energy crosses the hurdle, it will spur the entrepreneurs to action. Entrepreneurial intention focuses on the deep beliefs that lead to behaviour that is positively related to entrepreneurial action and subsequently outcome.

When the entrepreneur discovers an opportunity in a particular space-time, the entrepreneur's energy state will be excited to the point that may lead to actions leading to different possible pathways. See Diagram 3. In the nexus, there is a convergence of the entrepreneur and the opportunity and this necessarily leads to action when there is sufficient excitation arising from the discovery of entrepreneurial opportunity. 


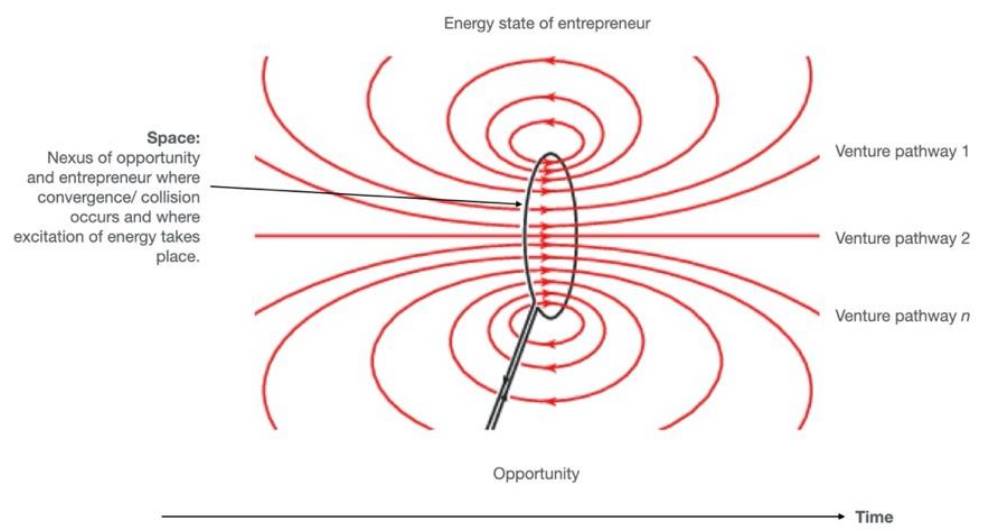

Diagram 3. nexus where convergence/ collision occurs with energy excitation (source: author's elaboration)

The primary sequence of activities in the discovery of entrepreneurial opportunities are discovery, recognition and interpretation- starting from framing/articulation, recognition/interpretation of the entrepreneurial opportunities. Structuration theory specifies discovery as an iterative process, taking place over time and space through the ongoing construction and reconstruction of the realities in the environment or entrepreneurial ecosystem (Sarason et al., 2006). The process of recognition/interpretation is a clinical analysis of the opportunity and may not necessarily lead to actions due to lack of excitement or entrepreneurial energy. Not every opportunity produces the same level of excitement and entrepreneurial energy that can spur entrepreneurs to actions. Hence, not all opportunities are created equal. Opportunities do not exist, in space, "a priori" waiting to be discovered but manifest to the entrepreneur and others who can perceive and recognize as they are conceptualized and are developed by the entrepreneur as part of the venturing process. The creative act that follows after the discovery and 203 
evaluation together with resource acquisition to support the new conceptualization is the venturing process. Diagram 4 shows the different possibilities of convergence between the entrepreneur and the opportunity. Where there is a collision or meeting at the nexus, the subsequent action that follows depend on the energy excitation that may lead to the different pathways.

In (a), the entrepreneur (E) and the opportunity converge with the opportunity (O), itself, do not excite the entrepreneur adequately but the entrepreneur shifts direction to proceed over time to meet with another opportunity (O2) and this time, the convergence leads to a shift in the direction shown by the line $(\mathrm{P})$.

In (b), the entrepreneur (E) and the opportunity converge with the opportunity (O) and spark an excitement, with an energy excitation shown in (A) with the recognition of the specific opportunity and producing possibilities of different venture pathway P1, P2, Pn... At P1, with the presence of another opportunity (O2), pathway P1.1 is created.

In (c), the entrepreneur (E) converges with two opportunities (O1) and $(\mathrm{O} 2)$ and recognizing both of them causes energy excitation to create two possible pathways $\mathrm{P} 1$ and $\mathrm{P} 2$. The entrepreneur takes a creative turn with excitation to produce possible pathways P3, P4 and Pn at that same space-time.

In (d), the entrepreneur (E) converged with two opportunities (O1) and $(\mathrm{O} 2)$ and recognizing both of them cause energy excitation to produce a possible pathway A, with energy excitation generating possible pathway P1 and $\mathrm{P} 2$. The entrepreneur has a creative recombination of resources to gen- 
erate pathway A3 at the same nexus, with excitation to produce possible pathways P3, P4, Pn.

Another scenario shows pathway $\mathrm{N}$, after the initial convergence with (01) and (O2) but the entrepreneur is in a non-excitable state until discovering and recognition of opportunity (O3) to create an energy excitation to lead to possible pathway A2.

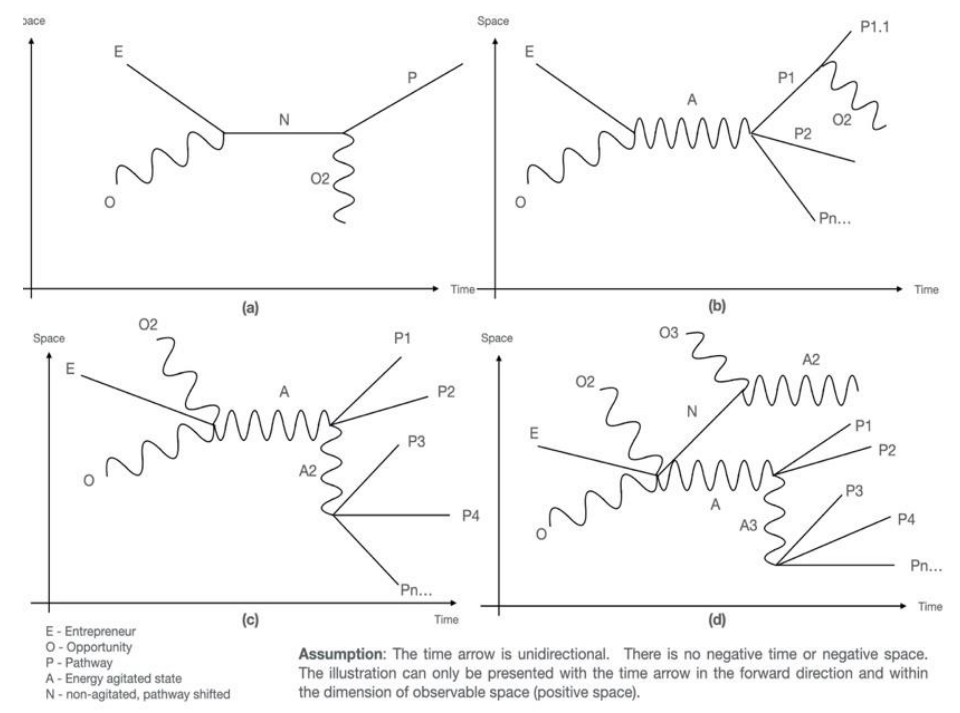

Diagram 4. collision and scattering pathways with energy excitation (source: author's elaboration)

Entrepreneurs need the creativity and morph-ability to see that the external environment and constraints are fluid and constantly changing, with opportunities and risks presenting themselves along the timeline, which is in the same constant state of flux as their own entrepreneurial venture. The changing of courses and the many pathway possibilities, as shown in Diagram 4, depend on the decisions and the entrepreneurial energy excitation at 
each stage that lead to the multi-finality possibilities. Pathway development is a function of the state of energy excitation to take specific actions and the decision at the nexus (space) and time.

Therefore, the sources of opportunities; the processes of discovery, evaluation, and exploitation of opportunities; where the core of entrepreneurship resides is in the nexus of opportunities and the entrepreneur (Shane \& Venkataraman, 2000).

Entrepreneurship is presented within the space as illustrated in Diagram 4 - the nexus of opportunity and the entrepreneur, whereby opportunities are not singular phenomena, but are idiosyncratic to the individual through the individual's unique recognition of the opportunities $(\mathrm{O})$. Recognition of the entrepreneurial opportunities is a subjective process, the opportunities themselves are objective phenomena. The same phenomenon may not be recognized as opportunity by others; hence the nature of idiosyncrasies of the entrepreneur needs to be accounted for. The instantiated view of opportunity is unique (Sarason et al., 2006). The instantiated view by itself may not necessarily lead to action described as $(\mathrm{N})$ in Diagram 4 as there may not be adequate entrepreneurial force or energy to drive the individual to action. The view must be coupled with a sense of do-ability and achievability for the individual to initiate a course of action that will lead to a venture pathway. Hence, opportunities, do not exist singularly but are brought into being by entrepreneurs as they discover through space and over time through their idiosyncratic perception and subsequent actions arising from the entrepreneurial energy. 
Exploration and discovery are one part, perception and identification are another part, inspired and motivated to move into action are the third part but each part does not necessarily follow the next sequentially. Some may explore and discover and stop short of recognizing the phenomena as opportunity. Some may explore, discover and identify the opportunity but stop short of being motivated adequately to move into action. What specifically spur the entrepreneurs to action? In this context, entrepreneurial energy is the mediation force that spurs action on a course of activities to actualization- from discovery and recognition to a point of monetization and exploitation. Hence it is important to note that entrepreneurs do not recognize the same phenomena and pursue them as the same opportunities. Entrepreneurs' unique perspectives direct them to view their opportunities idiosyncratically and to construct their unique ventures around their idiosyncratic interpretations and thereafter with sufficient force of the entrepreneurial energy to result in actionable processes. There must be a meeting at the nexus between the entrepreneur and the opportunity - a convergence or a collision in the space-time to produce an emergence event.

Entrepreneurial pathways and outcomes are a result of the entrepreneurs' actions triggered by entrepreneurial energy and the decision made at each juncture. The entrepreneur also creates opportunities through the recursive processes of discovery, recognition and interpretation and with each opportunity identified and recognized, the entrepreneur will have an energy bump to move them to action. The primary thrust of structuration theory is that entrepreneurs and structures of opportunities set within the space (Sara- 
son et al., 2010) and they co-evolve along the arrow of time. The entrepreneurs interpret their perceived realities and act on these interpretations. Through their idiosyncratic interpretation of opportunities, entrepreneurs need to be motivated adequately to spring into actionable process and set motion into events in a manner for effective exploration and exploitation. The level of motivation must come from an energy bumps to shift into actions. Diagram 6 shows an illustration of energy bump.

In this respect, the entrepreneurial process is highly path-dependent on the decision at the nexus, and the development of the possible venture pathways are idiosyncratic implying that the venture pathway development, as envisioned and implemented by one entrepreneur, is not necessarily readily accessible to others in the same setting and context.

There is an iterative cycle of entrepreneurial ventures creation and development- (1) the individual entrepreneur's idiosyncratic conceptualization; (2) the action engendered by that conceptualization arising from the entrepreneurial energy; (3) the development of possible venture pathways, intended and unintended, following from those actions in taking a specific pathway to proceed; and (4) the entrepreneur's reflection on, and response to, the consequences of the actions necessitating decision to stay the course or change direction. This iterative and recursive process moves along an entrepreneurial energy curve the rises and fall driving actions - specific actions to be taken when the energy is high and the individual is motivated and pumped up; similarly when the entrepreneurial energy decays as a result 
of failures, loss of direction or de-motivation, a halt of the process to reflect and to subsequently respond to find new means to proceed. See Diagram 5.

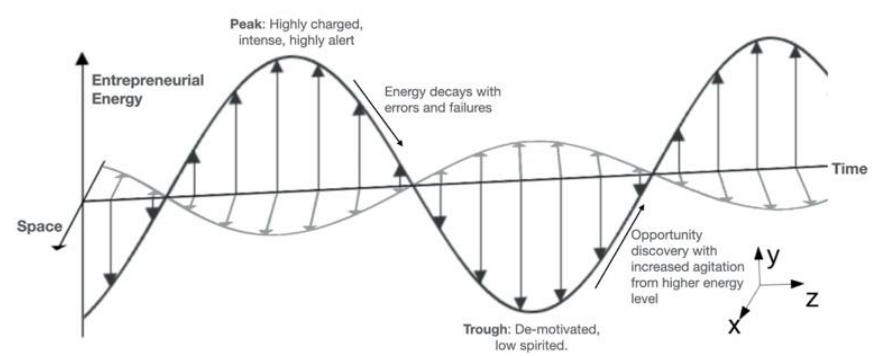

Diagram 5. Entrepreneurial energy curve (source: author's elaboration)

The implication of this recursive process is the entrepreneur creates new structures through new means and organization of resources through a co-evolutionary process of actions and consequences that are inherently dependent upon the conceptualization of the entrepreneur, since that conceptualization can generate consequential action. In summary, a particular course of action is unique because the idiosyncratic trajectory is created by the entrepreneur's conceptualization in a particular space-time instantiation. When seen in the nexus of opportunity and entrepreneur, entrepreneurial ventures are not only the result of conceptualization by individuals but are also created by them through a reflexive, recursive and iterative process (Sarason et al., 2006). The same object of an opportunity exists in the same space, but due to the subjective interpretation of the opportunity, different pursuits and pathways arise for the different entrepreneurs. See Diagram 6. The opportunity presented, depending on the interpretation of the different 209 
entrepreneurs will elicit different responses and energy excitation. A structuration perspective would, therefore pivot on a different portrayal of opportunity. The theory argues that social and economic systems become real or meaningful to the entrepreneur at the moment of interaction with other resources and opportunities. The concept of interaction is the operative definition of structuration (Sarason et al., 2006).

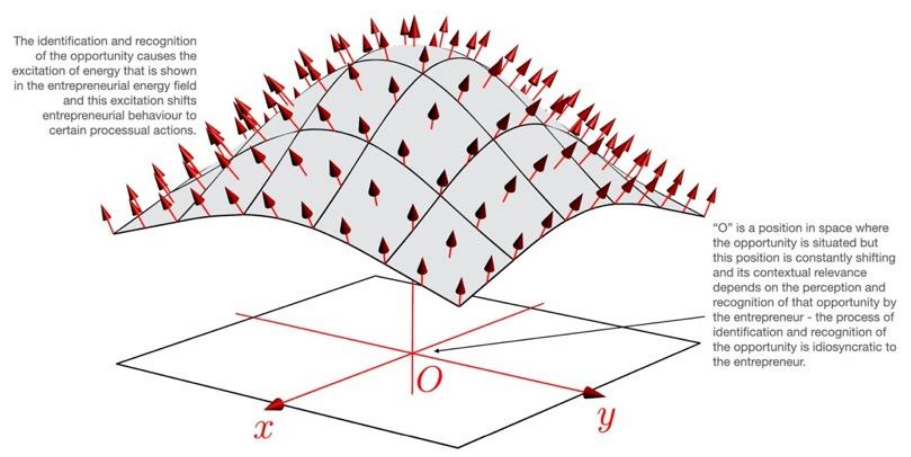

Diagram 6. an illustration of excited field fluctuation (source: author's elaboration)

A venture success or failure depends on the venture outcome but is not definitive as long as the entrepreneur continues on the entrepreneurial journey, and such an incident of success or failure is just part of the continuing curve. The curve extension or continuation of play is when the entrepreneurial energy is vibrating in keeping the entrepreneur upbeat despite failures or obstacle and in providing the impetus to continue looking for new ways, means and access to break away from the stalemate to find a solution out of a predicament or failure. The venture success or failure is a result of 
the consequences from actions arising from the decision at each nexus where there are multiple interactions with other agents, resources, network and other variables interfacing with each other in this instantiated world. Structuration theory implies that opportunities are not separate from the entrepreneur in that opportunities take form and are constructed and built upon, along the arrow of time, as the entrepreneur makes sense of it, and that through the process of defining, shaping and evaluating opportunities, the entrepreneurial process emerges. A more complete theorizing of the entrepreneurial process must include the dynamic interaction of the entrepreneur and the opportunity. The entrepreneur is viewed as a reflexive agent engaging in purposeful action through the interpretation of the opportunity or risk in a dynamic space within the entrepreneurial ecosystem (Sarason et al., 2006).

The act of entrepreneurship occurs as the agent specifies, interprets, and acts upon the sources of opportunity. This dynamic process whereby the sources of opportunity, in the context where the entrepreneur exist in that space, are acted on by the entrepreneur, and correspondingly the entrepreneur is affected by the sources of opportunity. Structuration theory provides that theoretical perspective on the process of constant interactivity, interdependence and dynamism in entrepreneurship.

\section{From the Perspective of Complex Science}

Metaphorizing complexity within the entrepreneurial ecosystem and space is essential for ease of understanding since there are many variables, 211 
including opportunities, risks, constraints and resources within the space in which the entrepreneurs operate. The operative space is a complex system. Complexity science focuses on order creation, hence is a better platform for a science of entrepreneurship (McKelvey, 2004). The metaphors direct the understanding based on certain perspectives to frame the cognitive and mental maps to produce a more dynamic understanding of the phenomenon between entrepreneurs and the space within a complex system (Lichtenstein, 2011).

Complexity science is presented as an alternative theoretical lens for addressing the complex interlacing and interactions in the entrepreneurial ecosystem/ space characterized by fluctuations, irreversibility, nonlinearity, and instabilities. Using this lens, entrepreneurial venturing centres on the notion of an opportunity space and a paradigm built around forms, flows, and functions (Schindehutte \& Morris, 2009). The domain consists of a complex set of phenomena that cannot be neatly bundled and stereotyped according to fixed disciplinary boundaries. Complexity includes selforganization, far-from-equilibrium, nonlinear dynamics, sensitive dependence on initial conditions, and edge of chaos (Schindehutte \& Morris, 2009).

Complexity science has extended to provide insights for entrepreneurship to capture the nonlinear nature of entrepreneurial action, and on emergence and the "coming-into-being" of new entrepreneurial entities such as opportunities (Lichtenstein, 2011). The view of entrepreneurial organizing as a dynamic state, in a dense network of opportunities, risks, relationships, constraints and resources that conjure entrepreneurial opportunity and 
translating that opportunity into a tangible value for the entrepreneur through gathering resources for the entrepreneurial organizing. Complexity science is suited for the exploration and descriptions of the complex dynamics of entrepreneurial systems. Framing the entrepreneurial venturing startup process as a discontinuous change of state, dynamical with irreversibility, nonlinearity and instabilities (Schindehutte \& Morris, 2009) to describe new venture emergence. New venture development in terms of cycles of emergence and re-emergence through which entrepreneurs configure and reconfigure their vision, strategy and resources to stay current with rapidly changing environments and perceptions. Constantly changing in a dynamic way with on emergence, "coming-into-being", punctuated shift in direction, decimation, re-emergence are all forms in the flow of chaos.

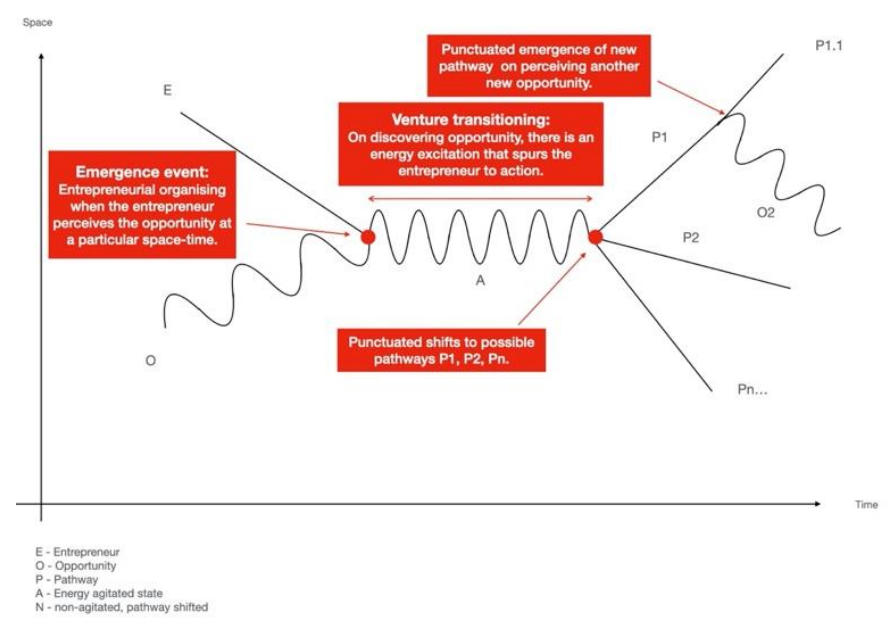

Diagram 7. emergent event and multi-pathways scenarios (source: author's elaboration) 
At the heart of entrepreneurship research is the emergence in the context of space - whether the creation of a venture or other organized entity through a dynamic organizing process (Lichtenstein, 2011), or the coming-into-being of new resources and means that lead to innovative creation of new recombinants using local resources at hands. A critical focus of entrepreneurship research is the emergence of new ventures, their transformation, decimation or re-emergence through other innovative reconstruction and the constant changing and shifting of venture pathways is common in the entrepreneuring process. The central role of emergence is evident in studies of entrepreneurial actions through organizing (McMullen \& Shepherd, 2006), entrepreneurial networks (Jack et al., 2008), opportunity recognition and creation. Complexity science can address the emergent phenomena at multiple levels of analysis, and both highlight the importance of nonlinear and unpredictable processes that generate emergent order in dynamic systems (Churchill \& Bygrave, 1989).

Diagram 7 shows a schematic diagram on the flow starting with an emergence event when the entrepreneur perceives and recognize the opportunity, and there is an entrepreneurial energy bump to cause sufficient excitation to move the entrepreneur to action. Emergence refers to the arising of novel and coherent structures, patterns and properties which can be collectively known as form in complex systems. Lichtenstein et al. (2006) define an emergence event is a coordinated and punctuated shift in multiple modes of entrepreneurial organizing at virtually the same time which generate a qualitatively different state- a new identity- within a nascent venture. 
The entrepreneurial ecosystem components embrace complexity. The venture-level complexity within the entrepreneurial ecosystems has three related forces that will influence entrepreneurial ecosystem emergence: intentionality of entrepreneurs, coherence of entrepreneurial activities, and injections of resources (Roundy et al., 2018) and each of these forces is dependent on the entrepreneurial energy that arises as a result of the convergence with opportunities.

\section{Conclusion}

This paper uses the structuration theory and complexity science, the entrepreneurial journey's dynamism with self-organization, far-fromequilibrium, nonlinear dynamics, sensitive dependence on initial conditions, and the edge of chaos define the conditions under which the entrepreneurs operate within. To this end, venture emergence to maturity are punctuated by many episodic and sessional events spur by decisions and actions taken by entrepreneurs spurred by entrepreneurial energy which characterize the entrepreneurial journey in the spatial-temporal scale. Until venture launch with the emergence and punctuated events, as described by Diagram 4 and Diagram 7, perceived by the entrepreneurs, entrepreneurial energy drives the progression of the entrepreneurial journey. The artefacts generated by the stages of the entrepreneurial process serve as the markers of progression of the journey. The combination of the discrete actions arising from entrepreneurial energy and continuous changes of the entrepreneurial journey trajectory in the opportunity space is what entrepreneurship is all about. Not 215 
every venture ends with success with safe landing as failures are likely to make more punctuations along with the trajectories/ pathways. With this paper, it is hoped that the entrepreneurial energy is seen as an important force contributing to existing approaches towards a greater understanding of the entrepreneurial journey and process concepts by examining the interconnection, interactivity and inter-dependability between the entrepreneurial process, journey, venture emergence, maturity, time and space.

\section{References}

1. Cardon, M. S., \& Stevens, C. E. (2009). The discriminant validity of entrepreneurial passion. In Academy of Management 2009 Annual Meeting: Green Management Matters, AOM 2009. https://doi.org/10.5465/ambpp.2009.44244277

2. Churchill, N., \& Bygrave, W. D. (1989). The Entrepreneurship Paradigm (I); A Philosophical Look at Its Research Methodologies.

3. Collewaert, V., Anseel, F., Crommelinck, M., De Beuckelaer, A., \& Vermeire, J. (2016). When Passion Fades: Disentangling the Temporal Dynamics of Entrepreneurial Passion for Founding. Journal of Management Studies, 53(6), 966-995.

4. Fuller, T., \& Moran, P. (2001). Small enterprises as complex adaptive systems: a methodological question? Entrepreneurship \& Regional Development, 13(1), 47-63.

5. Gielnik, M. M., Spitzmuller, M., Schmitt, A., Klemann, D. K., \& Frese, M. (2015). "I put in effort, therefore I am passionate": Investigating the path from effort to passion in entrepreneurship. In Academy of Management Journal, 58(4), 1012-1031.

6. Hoogendoorn, B., van der Zwan, P., \& Thurik, R. (2019). Sustainable Entrepreneurship: The Role of Perceived Barriers and Risk. Journal of Business Ethics, 157(4), 1133-1154.

7. Jack, S., Dodd, S. D., \& Anderson, A. R. (2008). Change and the development of entrepreneurial networks over time: A processual perspective. Entrepreneurship and Regional Development, 20(2), 125-159.

8. Krueger, N. F. (2007). What Lies Beneath? The Experiential Essence of Entrepreneurial Thinking. 
9. Lichtenstein, B. B. (2011). Complexity Science Contributions to the Field of Entrepreneurship. In Benyamin B Lichtenstein The Sage handbook of complexity and management, 471-493. https://www.researchgate.net/publication/228597717

10. Lichtenstein, B. B., Dooley, K. J., \& Lumpkin, G. T. (2006). Measuring emergence in the dynamics of new venture creation. Journal of Business Venturing, 21(2), 153-175.

11. McKelvey, B. (2004). Toward a complexity science of entrepreneurship. Journal of Business Venturing, 19(3), 313-341.

12. McMullen, J. S., \& Shepherd, D. A. (2006). Entrepreneurial action and the role of uncertainty in the theory of the entrepreneur. In Academy of Management Review, 31(1), pp. 132-152.

13. Roundy, P. T., Bradshaw, M., \& Brockman, B. K. (2018). The emergence of entrepreneurial ecosystems: A complex adaptive systems approach. Journal of Business Research, 86, 1-10.

14. Sarason, Y., Dean, T., \& Dillard, J. (2006a). Entrepreneurship as the Nexus of Individual and Opportunity: A Structuration View DLU-JOS CALL FOR PAPERS: Special Issue on Entrepreneurship and Innovation, and Social Entrepreneurship View project. Article in Journal of Business Venturing. https://doi.org/10.1016/j.jbusvent.2005.02.007

15. Sarason, Y., Dean, T., \& Dillard, J. F. (2006b). Entrepreneurship as the nexus of individual and opportunity: A structuration view. Journal of Business Venturing, 21(3), 286-305.

16. Sarason, Y., Dillard, J. F., \& Dean, T. (2010). How can we know the dancer from the dance? Reply to "Entrepreneurship as the structuration of individual and opportunity: A response using a critical realist perspective". (Mole and Mole, 2008). In Journal of Business Venturing, 25(2), 238-243.

17. Schindehutte, M., \& Morris, M. H. (2009). Advancing Strategic Entrepreneurship Research: The Role of Complexity Science in Shifting the Paradigm.

18. Shane, S. (2003). A general theory of entrepreneurship: The individual-opportunity nexus. A General Theory of Entrepreneurship: The Individual-Opportunity Nexus, 1-327.

19. Shane, S., \& Venkataraman, S. (2000). The Promise of Enterpreneurship as a Field of Research. In Source: The Academy of Management Review, 25(1), 1-12.

20. Stroe, I. S. (2017). The Duality of Passion in Entrepreneurship. Hanken School of Economics. 
David Leong, PhD started his entrepreneurial ventures early, soon after he graduated from the National University of Singapore in 1994 with a Bachelor of Business Administration degree. He has founded various ventures from corporate finance, business consultancy, design consultancy, human resources (HR), publication and technology. David was awarded his $\mathrm{PhD}$ from Charisma University in 2020 and is pursuing his Doctor of Business Administration with the University of Canberra for a double doctorate. His research is in entrepreneurship, and he is venturing to define "entrepreneurial energy" as the energy field spurring entrepreneurial actions in the light of complex science and quantum science. His other research area is in the Chinese Yijing, and he draws the relatedness of Yijing with modern science in particular quantum physics. http://straitstrades.com/david/ 